\title{
Integrin Alpha4 as a Therapeutic Target of Acute Lymphoblastic Leukemia
}

\section{Eun Ji Gang*, Yao-Te Hsieh and Yong-Mi Kim*}

Department of Pediatrics, Division of Hematology and Oncology, Children's Hospital Los Angeles, Keck School of Medicine, University of Southern California, Los Angeles, CA, USA

Acute lymphoblastic leukemia (ALL), characterized by malignancy originated from T- or B- lymphoid progenitors, accounts for $80 \%$ of childhood leukemia [1,2]. The incidence of ALL appears a bimodal age pattern and the first peak occurs at ages between 1 and 4 years with a decrease at ages 20 to 59 years, followed by the second peak (modest rise) at ages over 60 years [3]. Though overall cure rates have achieved $85 \%$ to $90 \%$ in children and $40 \%$ to $50 \%$ in adults with this disease by current intensive chemotherapy regimens, relapse affects $10 \sim 20 \%$ of children and $\sim 50 \%$ of adults [4-6]. Long-term survival rate for relapsed ALL ranges 30\% 35\% resulting in the most common death cause in children malignancies, which demands novel therapy modules with effectively targeting drug resistant leukemia clones $[5,6]$.

Bone marrow (BM) microenvironment or hematopoietic stem cell (HSC) niches, which consist of cellular components including osteoblasts, osteoclasts, endothelial cells, mesenchymal stem or stromal cells (MSCs), and extracellular matrix (ECM) [7-9]. Both of osteoblastic and vascular niches are critical for localizing, selfrenewal and differentiation of normal HSC and leukemia cells $[8,9]$. Physically, the marrow microenvironment provides a site for leukemia cells escaping from conventional chemotherapy [10]. These remaining small numbers of leukemia cells, i.e. minimal residual disease (MRD) contribute to relapse of the disease causing failure of treatment [11]. To understand how to effectively eradicate there resistant clone is critical to enhance the cure rate of ALLs.

Integrins, heterodimeric transmembrane glycoproteins consisting of various $\alpha$ and $\beta$ subunits play important role in adhesion mediated by cell-cell and cell-matrix interaction. In a total, there are 18 different $\alpha$ chains and $8 \beta$ subunits in humans, which form at least 24 distinct $\alpha / \beta$ integrin heterodimers [12]. In addition to function of adhesion, integrins also trigger intracellular signaling pathway such as $\mathrm{PI} 3 \mathrm{~K} / \mathrm{Akt} / \mathrm{Bcl} 2$ to regulate the cells in migration, homing, proliferation, differentiation and resistance to apoptosis, thereby contributing to drug resistance of leukemia. Among these 24 integrins, integrin a 4 is one of the wellstudied molecules over the last decade $[13,14]$. VLA-4 (Very Late Antigen-4), a noncovalently associated heterodimer of $\alpha 4$ (CD49d) and $\beta 1$ (CD29) subunits, is a receptor for vascular cell adhesion molecule-1 (VCAM-1/CD106) and fibronectin expressed by MSCs [12]. Integrin a4 (CD49d) or VLA-4 is normally expressed in leukocytes including B- and activated T-lymphocytes. Integrin $\alpha 4$ ( $\alpha 4$ ) has been shown to play a particular important role in interactions between normal HSC or leukemia cells and the BM niches [10,15]. Deletion of a4 integrin gene using interferon-induced conditional knockout adult mice $(\mathrm{Mx}$. crea4flox/flox) resulted in a release of HSCs into circulation, which continued for 50 weeks [16]. Homing to the BM was partially inhibited in parallel to rapid increase uptake by the spleen and early engraftment was impaired in the mice with a4 deletion, indicating the role of $a 4$ in adhesion, migration and survival of HSCs [16].

Mudry et al. showed that the effect of Ara-C- and VP-16-induced cell cycle arrest and apoptosis was diminished by coculture of B-lineage ALL cells with stromal cells, suggesting the supportive role of bone marrow stromal cells in maintaining leukemic cell proliferation and survival during exposure to chemotherapy [17].The protective function of stromal cells from chemotherapy was contributed to adhesion and has been considered as the mechanism of MRD and relapse of ALL $[11,17]$. The B-cell precursor (BCP) ALL patients at diagnosis of first relapse with higher VLA-4 expression in their BM leukemia cells had significantly worse event-free and overall survival probabilities than those with lowers expression [18]. Interestingly, functionally blocking of VLA-4 using anti- VLA-4 antibody in BCP ALL cell line REH, which expresses high level of VLA-4, decreased the adhesion and the antiapoptotic protein BCL-2, and significantly abolished the cytoprotective effect of stromal cells (L87/4) in response to Ara-C [18].

Recently, Hsieh et al. demonstrated that conditional deletion of a4 enhanced the treatment efficacy of tyrosine kinase inhibitor, nilotinib [19]. Moreover, a 4 blockade using Natalizumab, a humanized antibody which has been used clinically to treat the patients with multiple sclerosis and Crohn's disease, deadhered primary human Pre-B ALL cells from stromal cells and sensitized ALL cells toward chemotherapy, proposing a4 inhibition combined with chemotherapy as a novel strategy for pre-B ALL treatment $[19,20]$. As normal cells also express a4, it would be important to determine the effects of integrin a4 blockade on normal hematopoietic cells. To this end, it has also been shown that $\alpha 4$ blockade using Natalizumab did not affect viability of normal pre-B cells compared to the control IgG4-treated cells as assayed over 48 hours, indicating no short-term toxicity of integrin blockade by Natalizumab on normal pre-B cells [19]. In addition, non-leukemic, immune competent wild type or a4-deficient mice were treated with chemotherapy for 4 weeks and in addition with Natalizumab, and blood counts were monitored to determine toxic effects on normal blood counts [19]. The kinetics of leukocyte and erythrocyte recovery were indistinguishable in the two groups of mice demonstrating that chemotherapy treatment of immunocompetent, a4-deficient mice did not result in excessive hematopoietic toxicity against normal cells. Further toxicity studies including long-term studies of Natalizumab need to be further investigated.

In addition to functional blocking antibody, small molecules have been developed in an attempt to regulate integrin VLA-4 dependent adhesion [21]. Chigaev et al. identified several structurally related

*Corresponding author: Eun Ji Gang, Department of Pediatrics, Division of Hematology and Oncology, Children's Hospital Los Angeles, Keck School of Medicine, University of Southern California, Los Angeles, CA90027, USA, Tel: (323)361-6555; E-mail: ejiang@chla.usc.edu

Yong-Mi Kim, Department of Pediatrics, Division of Hematology and Oncology, Children's Hospital Los Angeles, Keck School of Medicine, University of Southern California, Los Angeles, CA90027, USA, Tel: (323)361-8544; E-mail:ymkim@chla.usc.edu

Received December 24, 2013; Accepted January 28, 2014; Published February 04, 2014

Citation: Gang EJ, Hsieh YT, Kim YM (2014) Integrin Alpha4 as a Therapeutic Target of Acute Lymphoblastic Leukemia. J Blood Disorders Transf 5: 196. doi: 10.4172/2155-9864.1000196

Copyright: @ 2014 Gang EJ, et al. This is an open-access article distributed under the terms of the Creative Commons Attribution License, which permits unrestricted use, distribution, and reproduction in any medium, provided the original author and source are credited. 
Citation: Gang EJ, Hsieh YT, Kim YM (2014) Integrin Alpha4 as a Therapeutic Target of Acute Lymphoblastic Leukemia. J Blood Disorders Transf 5: 196. doi: 10.4172/2155-9864.1000196

Page 2 of 2

compounds that were able to reduce binding affinity of VLA-4- specific ligand, and block VLA-4/VCAM-1-dependent cell adhesion [22]. The compounds disrupted the adhesion of the cells in vitro, and mobilized HSC from BM to the peripheral blood, which raises therapeutic possibilities of these small molecules for VLA-4-related malignancies including ALL.

In summary, a role of microenvironment in protecting ALL cells from chemotherapy has been implicated [10,11]. Disruption of the adhesion between ALL cells and the BM stroma has been shown to promote a release of ALL cells from BM to peripheral blood, where chemotherapy might more effectively attack leukemia cells [19]. The exact mechanistic contribution of integrin a 4 to drug resistance of leukemia remains to be determined to develop blockade of integrin a4 using either antibody or small molecules for clinical care.

\section{Acknowledgement}

YM Kim acknowledges support by grants from the V-foundation, St. Baldrick's Foundation, Hyundai Hope on Wheels and R01CA172896

\section{References}

1. Pui $\mathrm{CH}$, Evans WE (2006) Treatment of acute lymphoblastic leukemia. N Eng J Med 354: 166-178.

2. Pui CH, Robison LL, Look AT (2008) Acute lymphoblastic leukaemia. Lancet 371: 1030-1043.

3. Dores GM, Devesa SS, Curtis RE, Linet MS, Morton LM (2012) Acute leukemia incidence and patient survival among children and adults in the United States, 2001-2007. Blood 119: 34-43

4. Onciu M (2009) Acute lymphoblastic leukemia. Hematol Oncol Clin North Am 23: $655-674$

5. Raetz EA, Bhatla T (2012) Where do we stand in the treatment of relapsed acute lymphoblastic leukemia? Hematology Am Soc Hematol Educ Program 2012: $129-136$

6. Reismüller B, Attarbaschi A, Peters C, Dworzak MN, Pötschger U et al. (2009) Long-term outcome of initially homogenously treated and relapsed childhood acute lymphoblastic leukaemia in Austria-a population-based report of the Austrian Berlin-Frankfurt-Munster (BFM) Study Group. Br J Haematol 144 $559-570$.

7. Calvi LM, Adams GB, Weibrecht KW, Weber JM, Olson DP, et al. (2003) Osteoblastic cells regulate the haematopoietic stem cell niche. Nature 425 : 841-846.

8. Méndez-Ferrer S, Michurina TV, Ferraro F, Mazloom AR, Macarthur BD, et al. (2010) Mesenchymal and haematopoietic stem cells form a unique bone marrow niche. Nature 466: 829-834

9. Ding L, Saunders TL, Enikolopov G, Morrison SJ (2012) Endothelial and perivascular cells maintain haematopoietic stem cells. Nature 481: 457-462.

10. Meads MB, Hazlehurst LA, Dalton WS (2008) The bone marrow microenvironment as a tumor sanctuary and contributor to drug resistance. Clin Cancer Res 14: 2519-2526.

11. Campana D (2010) Minimal residual disease in acute lymphoblastic leukemia Hematology Am Soc Hematol Educ Program 2010: 7-12.

12. Hynes RO (2002) Integrins: bidirectional, allosteric signaling machines. Cell 110: $673-687$.

13. Astier AL, Svoboda M, Hinds E, De Beaumont R, Munoz O, et al. (2004) Integrins regulate survival of pre-B-ALL cells through differential IAP and caspase-7 ubiquitination and degradation. Leukemia 18: 873-875.

14. de la Fuente MT, Casanova B, Moyano JV, Garcia-Gila M, Sanz L, et al. (2002) Engagement of alpha4beta1 integrin by fibronectin induces in vitro resistance of B chronic lymphocytic leukemia cells to fludarabine. J Leukoc Biol 71: 495-502.

15. Manabe A, Murti KG, Coustan-Smith E, Kumagai M, Behm FG, et al. (1994) Adhesion-dependent survival of normal and leukemic human $B$ lymphoblasts on bone marrow stromal cells. Blood 83: 758-766.

16. Scott LM, Priestley GV, Papayannopoulou T (2003) Deletion of alpha4 integrins from adult hematopoietic cells reveals roles in homeostasis, regeneration, and homing. Mol Cell Biol 23: 9349-9360.

17. Mudry RE, Fortney JE, York T, Hall BM, Gibson LF (2000) Stromal cells regulate survival of B-lineage leukemic cells during chemotherapy. Blood 96: 1926-1932.

18. Shalapour S, Hof J, Kirschner-Schwabe R, Bastian L, Eckert C, et al. (2011) High VLA-4 expression is associated with adverse outcome and distinct gene expression changes in childhood B-cell precursor acute lymphoblastic leukemia at first relapse. Haematologica 96: 1627-1635.

19. Hsieh YT, Gang EJ, Geng H, Park E, Huantes S, et al. (2013) Integrin alpha4 blockade sensitizes drug resistant pre-B acute lymphoblastic leukemia to chemotherapy. Blood 121: 1814-1818.

20. Cox D, Brennan M, Moran N (2010) Integrins as therapeutic targets: lessons and opportunities. Nat Rev Drug Discov 9: 804-820.

21. Jackson DY (2002) Alpha 4 integrin antagonists. Curr Pharm Des 8: 1229-1253.

22. Chigaev A, Wu Y, Williams DB, Smagley Y, Sklar LA (2011) Discovery of very late antigen-4 (VLA-4, alpha4beta1 integrin) allosteric antagonists. J Biol Chem 286: $5455-5463$ 